\title{
Voltage-Gated Sodium Channels and AnkyrinG Occupy a Different Postsynaptic Domain from Acetylcholine Receptors from an Early Stage of Neuromuscular Junction Maturation in Rats
}

\author{
Sarah J. Bailey, Mark A. Stocksley, Alexandra Buckel, Carol Young, and Clarke R. Slater \\ School of Neurology, Neurobiology Psychiatry, The Medical School, University of Newcastle upon Tyne, Newcastle upon Tyne NE2 4HH, United Kingdom
}

Spatial segregation of membrane proteins is a feature of many excitable cells. In skeletal muscle, clusters of acetylcholine receptors (AChRs) and voltage-gated sodium channels $\left(\mathrm{Na}_{\mathrm{v}} 1 \mathrm{~s}\right)$ occupy distinct domains at the neuromuscular junction (NMJ). We used quantitative immunolabeling of developing rat soleus muscles to study the mechanism of ion channel segregation and $\mathrm{Na}_{\mathrm{V}} 1$ clustering at NMJs. When $\mathrm{Na}_{\mathrm{V}} 1 \mathrm{~s}$ can first be detected, at birth, they already occupy a postsynaptic domain that is distinct from that occupied by AChRs. At this time, $\mathrm{Na}_{\mathrm{V}} 1 \mathrm{~s}$ are expressed only in a diffuse area that extends 50-100 $\mu \mathrm{m}$ from the immature NMJ. However, in the region of the high-density $\mathrm{AChR}$ cluster at $\mathrm{NMJ}$ itself, $\mathrm{Na}_{\mathrm{V}} 1 \mathrm{~s}$ are actually present in lower density than in the immediately surrounding membrane. These distinctive features of the $\mathrm{Na}_{\mathrm{V}} 1$ distribution at birth are closely correlated with the distribution of ankyrinG immunolabeling. This suggests that an interaction with ankyrinG plays a role in the initial segregation of $\mathrm{Na}_{\mathrm{V}} 1$ s from $\mathrm{AChRs}$. Both $\mathrm{Na}_{\mathrm{V}} 1$ and ankyrinG become clustered at the NMJ itself 1-2 weeks after birth, coincident with the formation of postsynaptic folds. Syntrophin immunolabeling codistributes with AChRs and never resembles that for $\mathrm{Na}_{\mathrm{V}} 1$ or ankyrinG. Therefore, syntrophin is unlikely to play an important part in the initial accumulation of $\mathrm{Na}_{\mathrm{V}} 1$ at the NMJ. These findings suggest that the segregation of $\mathrm{Na}_{\mathrm{V}} 1$ from AChRs begins early in NMJ formation and occurs as a result of the physical exclusion of $\mathrm{Na}_{\mathrm{V}} 1$ and ankyrinG from the region of nerve-muscle contact rather than by a process of active clustering.

Key words: neuromuscular junction; sodium channel; ankyrin; syntrophin; rat; development

\section{Introduction}

At the neuromuscular junction (NMJ) two classes of ion channel, occupying distinct postsynaptic domains, mediate the immediate response of vertebrate skeletal muscle fibers to the motor nerve. Acetylcholine receptors (AChRs), concentrated at the crest of the postsynaptic folds (Fertuck and Salpeter, 1974), generate an initial local depolarization in response to transmitter released from the nerve. Voltage-gated sodium channels ( $\mathrm{Na}_{\mathrm{V}} 1$ channels) (Goldin et al., 2000), concentrated in the depths of the folds and in the perijunctional membrane (Haimovich et al., 1987; Flucher and Daniels, 1989; Wood and Slater, 1998), convert this local depolarization into a propagating action potential (Martin, 1994). The juxtaposition of these distinct ion channel domains plays an important part in ensuring the effectiveness of neuromuscular transmission (Wood and Slater, 2001), but how they are generated and how the segregation of ion channels is maintained is not understood.

Previous studies have revealed clear differences between the

Received Sept. 6, 2002; revised Dec. 11, 2002; accepted Dec. 16, 2002

This work was supported by the Wellcome Trust. We thank Harvey Smith for writing the image analysis macros. Correspondence should be addressed to Prof. Clarke R. Slater, School of Neurology, Neurobiology and Psychiatry, The Medical School, University of Newcastle upon Tyne, Framlington Place, Newcastle upon Tyne NE2 4HH, UK. E-mail:c.r.slater@ncl.ac.uk.

S. J. Bailey's present address: Department of Biochemistry, University of Bristol, University Walk, Bristol BS8 1TD, UK. M. A. Stocksley's present address: Department of Cellular and Molecular Medicine, Faculty of Medicine, University of Ottawa, 451 Smyth Road, Ottawa, Canada K1H8M5.

Copyright $\odot 2003$ Society for Neuroscience $\quad 0270-6474 / 03 / 232102-10 \$ 15.00 / 0$ spatiotemporal patterns of $\mathrm{AChR}$ and $\mathrm{Na}_{\mathrm{V}} 1$ accumulation at developing mammalian NMJs. AChRs are expressed at a relatively low level all along immature muscle fibers, but clusters of much higher AChR density form at rat hindlimb NMJs within hours of the earliest nerve-muscle contacts, up to a week before birth (Bevan and Steinbach, 1977). In contrast, $\mathrm{Na}_{\mathrm{V}} 1$ channels cannot be detected using immunolabeling techniques until birth, when the pattern of labeling is suggestive of a diffuse zone of increased density in the vicinity of the NMJ (Wood et al., 1998). During the next 1-2 weeks, when the postsynaptic folds are forming (Bewick et al., 1996), the highly localized accumulation of $\mathrm{Na}_{\mathrm{V}} 1$ channels characteristic of the mature NMJ develops (Lupa et al., 1993), and $\mathrm{Na}_{\mathrm{V}} 1$ channels also appear along the rest of the muscle fiber surface (Wood et al., 1998; Stocksley and Slater, 1999). These observations have led to the suggestion that $\mathrm{Na}_{\mathrm{V}} 1$ channel clustering, unlike AChR clustering, is dependent on postsynaptic fold formation.

There is good evidence that the initial aggregation of AChRs at the NMJ involves interaction with cytoplasmic proteins, in particular rapsyn (Sanes and Lichtman, 1999). Much less is known about the factors causing $\mathrm{Na}_{\mathrm{V}} 1$ channel accumulation. Members of two families of cytoplasmic proteins present in muscle, ankyrins and syntrophins, have been shown to bind to $\mathrm{Na}_{\mathrm{V}} 1 \mathrm{~s}$ in vitro (Srinivasan et al., 1992; Gee et al., 1998) and are concentrated at mature NMJs (Peters et al., 1994; Kordeli et al., 1998; Wood and Slater, 1998). This suggests that one or both of these proteins might play a role in $\mathrm{Na}_{\mathrm{V}} 1$ accumulation during development. 
To investigate this possibility, we used immunolabeling to determine the distributions of these proteins during NMJ formation in vivo. We found evidence of the segregation of $\mathrm{Na}_{\mathrm{V}} 1$ channels from AChRs at birth, before fold formation had begun, so we then asked whether isoforms of ankyrin or syntrophin were already associated with $\mathrm{Na}_{\mathrm{V}} 1$ channels at this time. As an additional test of the hypothesis that the formation of postsynaptic ion channel domains is not dependent on fold formation, we investigated NMJs in adult chicken muscle that lack postsynaptic folds (Salpeter, 1987).

\section{Materials and Methods}

Tissues. Most of the studies were made on soleus muscles from newborn Wistar rats. The day of birth was considered postnatal day 0 (P0). For the muscles studied at embryonic day 18 (E18), the entire hindlimb was used. Muscles were prepared for immunolabeling in one of two ways, as described previously (Bewick et al., 1992; Wood and Slater, 1998). For viewing NMJs en face, immunolabeling was performed on teased fibers that were lightly fixed ( $1 \%$ paraformaldehyde in $0.1 \mathrm{~m}$ sodium phosphate buffer, $\mathrm{pH} 7.2$ for $1 \mathrm{hr})$ and permeabilized with Triton X-100 (0.1\% for $30 \mathrm{~min})$. In addition, immunolabeling was performed on transverse cryosections $(6 \mu \mathrm{m})$ of unfixed soleus muscles.

Some observations were also made of NMJs in the ambiens muscle of young adult (3-4-week-old) chickens (High Sex Brown strain). These were fixed and teased into small bundles in the same way as for rats. An overview of the structure of the NMJ was obtained by labeling the nerve with FM1-43 (Betz and Bewick, 1992) and AChRs with tetramethyl rhodamine isothiocyanate (TMRITC) $\alpha$-bungarotoxin $(\alpha$-BgTx) (see below). Ultrastructure was studied using conventional fixation, embedding, and sectioning procedures (Slater et al., 1992).

Antibodies. Primary antibodies, all of whose properties have been described previously, were diluted in PBS containing 3\% BSA and $0.1 \mathrm{~m}$ lysine. For our initial $\mathrm{Na}_{\mathrm{V}} 1$ labeling studies, the rabbit polyclonal antibody AP1380, raised against a peptide that is highly conserved in all $\mathrm{Na}_{\mathrm{V}} 1$ isoforms (a gift from Dr. R. Levinson, University of Colorado School of Medicine, Denver, CO) (Dugandzija-Novakovic et al., 1995) was used at a dilution of 1:30. In later studies, a monoclonal antibody raised against the same peptide (Rasband et al., 1999) was used (S8809, clone K58/35; Sigma, St. Louis, MO). Two antibodies were used to label ankyrinG: an affinity-purified rabbit polyclonal (AnkG@SpBd; a gift from Dr. Steve Lambert, Worcester Foundation for Biomedical Research, Shrewsbury, MA) (Kordeli et al., 1995) and a monoclonal antibody [obtained initially as a gift from Dr. Vann Bennett, Duke University, Chapel Hill, NC, and then commercially (clone 4G3F8) from Zymed Laboratories, San Francisco, CA], both used at a dilution of 1:100. The monoclonal antibody SYN1351 (Peters et al., 1997), which recognizes an epitope common to all forms of syntrophin, was used at a dilution of 1:500 (initially obtained as a gift from Dr. S. Froehner, University of Washington, Seattle, WA, and then from Dakocytomation, High Wycombe, UK).

TMRITC-conjugated swine anti-rabbit or rabbit anti-mouse Igs (Dakocytomation) were used to recognize polyclonal and monoclonal primary antibody labeling, respectively. For double-antibody-labeling experiments, monoclonal primary antibodies were detected using an FITC-conjugated goat anti-mouse Ig secondary antibody (Dakocytomation). All secondary antibodies were preincubated with normal rat serum, centrifuged, and then diluted at 1:100 (Bewick et al., 1996).

Chicken NMJs were labeled in teased bundles of muscle fibers. Antibody AP1380 was used to label $\mathrm{Na}_{\mathrm{V}}$ las described above. None of a number of antibodies directed against ankyrin was effective in labeling chicken muscles. $\alpha$-Fodrin, a form of $\alpha$-spectrin, was labeled with a monoclonal antibody raised against chicken red blood cell membranes (clone AA6; ICN Biomedicals, Basingstoke, UK) at a dilution of 1:50. Utrophin was labeled with monoclonal antibody DRP3/20C5 (Bewick et al., 1993).

Immunolabeling. All of the procedures used for immunolabeling are essentially the same as those described previously (Wood and Slater, 1998). Briefly, permeabilized teased muscle fibers were incubated in primary antibodies overnight at $4^{\circ} \mathrm{C}$. After washing, the fibers were incu- bated for $2 \mathrm{hr}$ in secondary antibodies that had been preincubated with normal rat serum at a ratio of 2:1 before dilution and application. To enable NMJs to be identified, FITC- $\alpha$-BgTx $\left(6 \times 10^{-7}\right.$ M; Molecular Probes, Eugene, OR), which labels AChRs, was added with the secondary antibody solution. Subsequently, the fibers were washed, fixed in paraformaldehyde, and then mounted on microscope slides in antifading fluorescence mounting medium (Vectashield, Vector Laboratories, Peterborough, UK). As a control, an identical labeling procedure was performed with the omission of the primary antibody in which diluent alone was applied. Slide-mounted transverse cryosections were briefly washed with Triton X-100 (0.1\%) in PBS before labeling with primary antibodies. The labeling procedure for cryosections was then the same as that for teased fibers.

To examine the colocalization of $\mathrm{Na}_{\mathrm{V}} 1$ with ankyrinG, double antibody labeling was performed. Frozen sections were incubated overnight at $4^{\circ} \mathrm{C}$ in a mixture of AP1380 and monoclonal antibody $4 \mathrm{G} 3 \mathrm{~F} 8$, followed by $1 \mathrm{hr}$ at room temperature. They were then incubated in a mixture of the two secondary antibodies for $2 \mathrm{hr}$ and washed and mounted in Vectashield.

Microscopy. Pairs of digitized images of double-labeled (FITC and TMRITC) cryosections and teased fibers were recorded, using 40-100X objectives, with one of two cooled CCD camera imaging systems: AstroCam (Cambridge, UK) on an M2B microscope (MicroInstruments Ltd., Oxford, UK) or SPOT-2 (Diagnostic Instruments, Inc., Sterling Heights, MI) on a Leica (Wetzlar, Germany) DMRA microscope. Suitable filter sets were used with each system to ensure that there was no significant cross-contamination of the FITC and TMRITC channels.

Analysis of fluorescent labeling. Digitized images were analyzed using Scion Image for Windows (Scion Corporation). Muscle fiber profiles containing NMJs were identified from the image of $\alpha$-BgTx labeling. The same profiles were identified in the image of antibody labeling and outlined with the freehand drawing tool to define a profile of interest (POI). Using a locally written macro, the intensity values (eight bit resolution) of the pixels underlying the POI were read out. To obtain a suitable value for the background intensity, the POI was converted into a binary area of interest (AOI), which was then eroded until its minor axis was $25 \%$ of that of the original AOI. The mean intensity within this eroded AOI was defined as the background value and was subtracted from each of the intensity values derived from the POI. These net intensity values, together with the corresponding distance from the starting point of the profile, were then saved in a text file. The same POI was then transferred to the $\alpha$-BgTx image, and the intensity corresponding to the same set of pixels was read out and saved. Corresponding pairs of text files were saved for each of 10-86 muscle fiber profiles from each muscle.

Averaged distributions, based on the saved intensity values, were calculated using an Excel macro (Microsoft, Seattle, WA). For each fiber, the macro scanned the array of data from the $\alpha$-BgTx image to find the peak of intensity and the two positions at which the intensity was $50 \%$ of the peak. Midway between those positions was taken as the position of the NMJ, was defined as "zero," and was placed at the center of a new array with equal numbers of intensity values on either side of it. The same distance transformations, based on the $\alpha$-BgTx data, were applied to the values from the images of antibody labeling, to form a corresponding array. To allow averaging of data from different fibers, with different shapes and perimeters, the values for each fiber were grouped into bins corresponding to $2 \mu \mathrm{m}$ increments of distance away from the NMJ and the average of the values in each bin was calculated. After binning the data for each fiber profile in a data set, values were removed from the ends of the individual arrays so that they were all the same length as the shortest array, corresponding to the fiber with the smallest perimeter. The values corresponding to each distance were then averaged, and the SEM of each distance bin was calculated.

Longitudinal reconstruction. To identify the extent of perijunctional labeling of $\mathrm{Na}_{\mathrm{V}} 1$ in muscles from newborn rats, serial transverse sections were cut through the region of innervation and individual fibers were identified from their shape and position in digital images of each of $\sim 30$ serial sections, each $6 \mu \mathrm{m}$ thick. For each fiber analyzed, the profile was traced, the mean of the underlying pixels was calculated, and the associated background was subtracted (see above). The mean intensity of sur- 
face labeling was then plotted as a function of distance from the NMJ (indicated by labeling of AChRs with $\alpha$-BgTx), assuming that each section was $6 \mu \mathrm{m}$ thick.

Processing of images for illustration. For the illustrations, images were processed with Adobe Photoshop 6 (Adobe Systems, San Jose, CA) to make clear the spatial variations in intensity within the image rather than to display faithfully the overall differences in intensity from one image to the next. The latter information is provided in the various graphs of labeling intensity in the figures.

\section{Results}

In newborn rat soleus muscles labeled with an antibody that recognizes all forms of $\mathrm{Na}_{\mathrm{V}}$ 1, increased labeling was observed near the zone of innervation of the muscle (Fig. 1). In contrast to AChR labeling, which was present in small, well defined clusters, $\mathrm{Na}_{\mathrm{V}} 1$ labeling was seen in a broad zone several hundred micrometers long. Away from the region of innervation, labeling intensity fell to background levels. AnkyrinG immunolabeling was strikingly similar to that of $\mathrm{Na}_{\mathrm{V}} 1$ labeling. In contrast, the pattern of labeling for syntrophin was very different. Fibers were clearly labeled all along their length, and there was an increase in labeling in the region of high AChR density. Thus, in newborn muscles, there are clear differences in the distribution of both the ion channels $\left(\mathrm{Na}_{\mathrm{V}} 1\right.$ and AChRs) and the cytoplasmic proteins (ankyrinG and syntrophin). We went on to characterize and compare these labeling patterns in more detail to gain insight into the mechanism of ion channel segregation at birth and the processes of $\mathrm{Na}_{\mathrm{V}} 1$ channel clustering.

\section{Accumulation of $\mathrm{Na}_{\mathrm{V}} 1$ channels at developing NMJs}

In contrast to AChRs, no well defined cluster of $\mathrm{Na}_{\mathrm{V}} 1$ labeling was present at the NMJ at birth. Figure $2 A$ shows that $1-2$ weeks after birth $\mathrm{Na}_{\mathrm{V}} 1$ labeling was apparent at the NMJ and by P28 resembled the adult distribution. Previous studies have shown that $\mathrm{Na}_{\mathrm{V}} 1.4$, the adult form of muscle $\mathrm{Na}_{\mathrm{V}} 1$, does not become concentrated in the postsynaptic membrane of rat NMJs until 2-3 weeks after birth (Lupa et al., 1993). We were interested to know whether there was an earlier accumulation of $\mathrm{Na}_{\mathrm{V}} 1.5$, the fetal form. Because an antibody that labels $\mathrm{Na}_{\mathrm{V}} 1.5$ specifically is not available, we also used an antibody specific for $\mathrm{Na}_{\mathrm{V}} 1.4$. No labeling was seen in sections of muscles at P0 (data not shown), but it was present from P14 on, confirming the low levels of $\mathrm{Na}_{\mathrm{V}} 1.4$ early in development (Lupa et al., 1993). Thus, at birth, most of the $\mathrm{Na}_{\mathrm{V}} 1$ we detected in the perijunctional region using an antibody that recognizes all forms of $\mathrm{Na}_{\mathrm{V}} 1$ (DugandzijaNovakovic et al., 1995) was $\mathrm{Na}_{\mathrm{V}} 1.5$. This study of whole-fiber preparations revealed no highly localized concentration of either the adult $\left(\mathrm{Na}_{\mathrm{V}} 1.4\right)$ or the fetal $\left(\mathrm{Na}_{\mathrm{V}} 1.5\right)$ form at the $\mathrm{NMJ}$ itself in newborn rats.

Analysis of the intensity of immunolabeling of $\mathrm{Na}_{\mathrm{V}} 1$ around the circumference of developing muscle fibers confirmed our subjective impression that there was no obvious clustering of $\mathrm{Na}_{\mathrm{V}} 1$ labeling at the NMJ itself at birth (Fig. 2 B,C). We recorded circumferential labeling distributions for samples of 12-14 muscle fibers containing NMJs labeled by FITC- $\alpha$-BgTx and averaged them to reduce the effects of variation around fibers (see Materials and Methods). These averaged distributions show clearly that the local increase in $\mathrm{Na}_{\mathrm{V}} 1$ labeling intensity, characteristic of mature NMJs, does not appear until 1-2 weeks after birth (Fig. 2C). This is in marked contrast to the labeling for AChRs, which is clearly increased at the NMJ at birth and is well known to be concentrated there for a number of days before birth (Bevan and Steinbach, 1977).
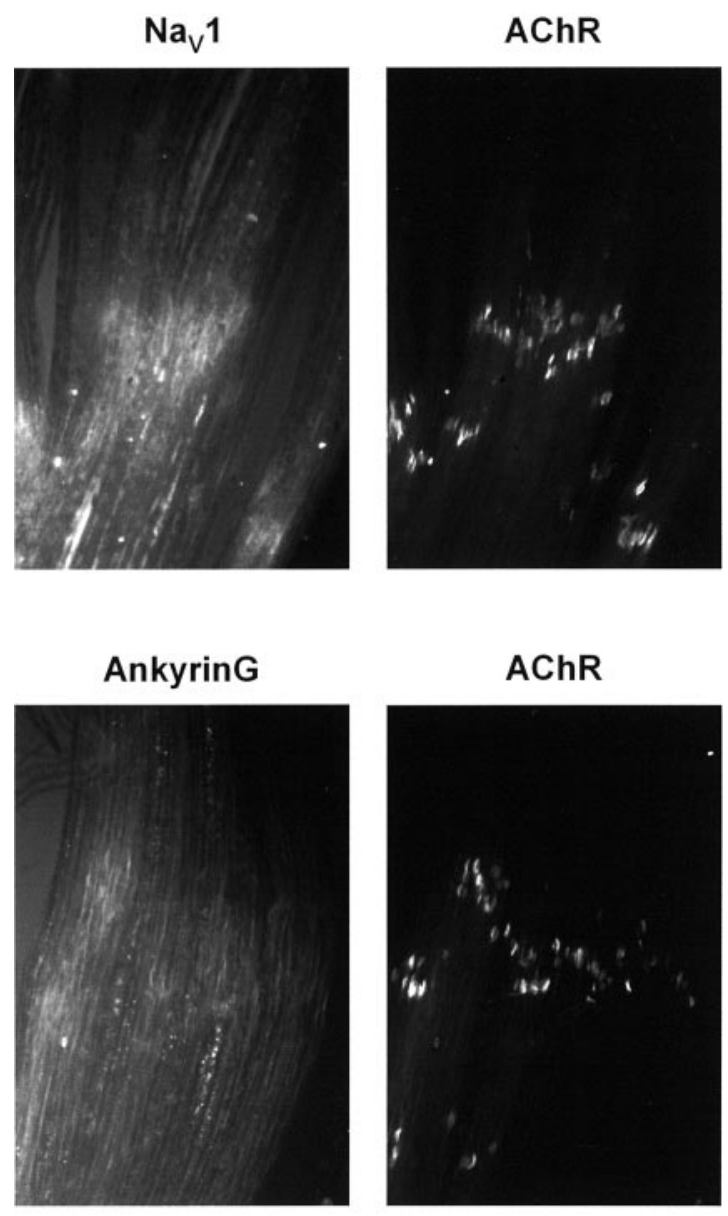

Syntrophin

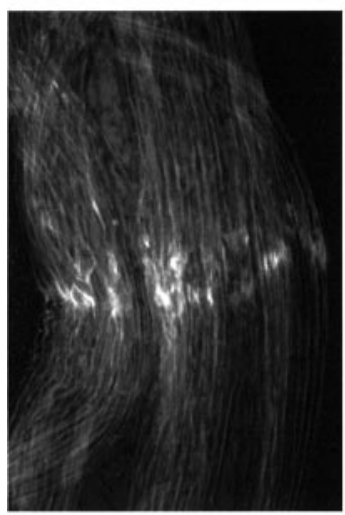

$\mathrm{AChR}$

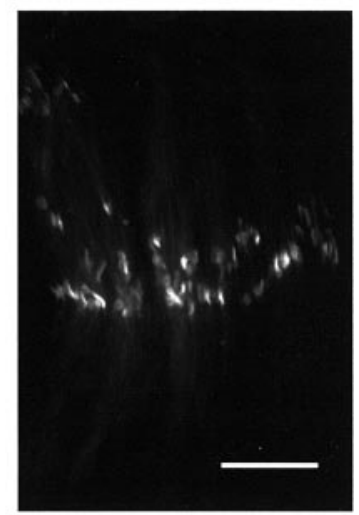

Figure 1. Distribution of $\mathrm{Na}_{v} 1$, ankyrinG, and syntrophin in soleus muscles from newborn rats. $\mathrm{AChRs}$ are tightly clustered at the NMJs but undetectable elsewhere. $\mathrm{Na}_{\mathrm{v}} 1$ and ankyrinG are increased within $\sim 100 \mu \mathrm{m}$ of the NMJs but are not tightly clustered. Syntrophin is present in the surface membrane all along the muscle fibers and is particularly concentrated at the NMJs in a region corresponding to the $A C h R$ cluster. Scale bar, $100 \mu \mathrm{m}$.

At P0, most fiber profiles that contained labeled NMJs also had a high level of surface labeling for $\mathrm{Na}_{\mathrm{V}} 1$, although there were many profiles labeled for $\mathrm{Na}_{\mathrm{V}} 1$ that did not include NMJs (Fig. $2 B$, asterisk). This suggested that the increased circumferential labeling reflected the presence of a perijunctional region of relatively high $\mathrm{Na}_{\mathrm{V}} 1$ density that extended along the muscle fiber away from the NMJ (Fig. 1). To determine the extent of this region along individual fibers, we made a longitudinal recon- 
A.

P7
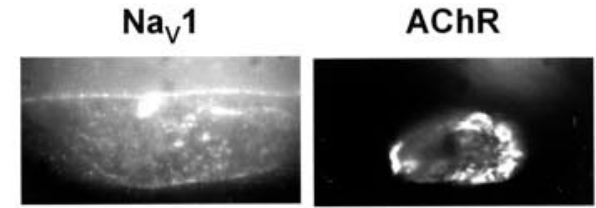

P14
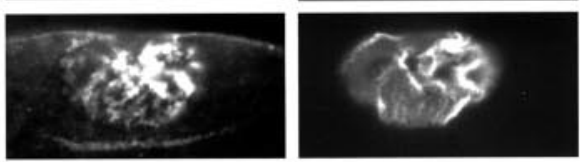

P21
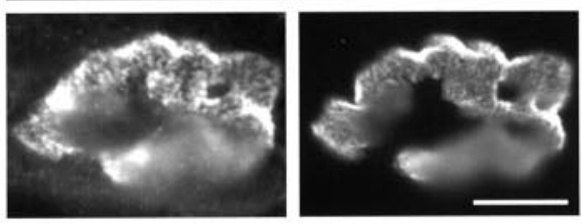

B.

PO
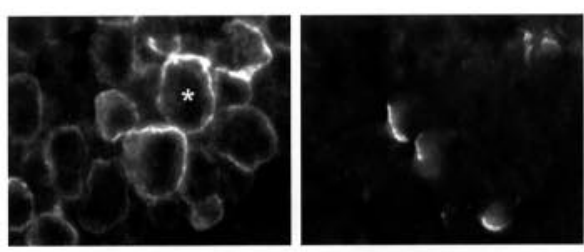

P14
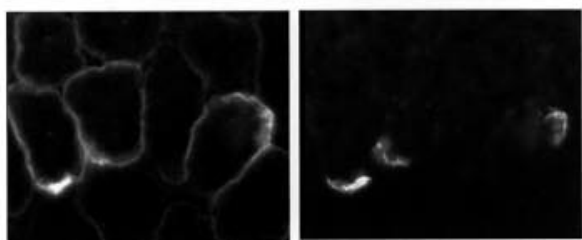

P28
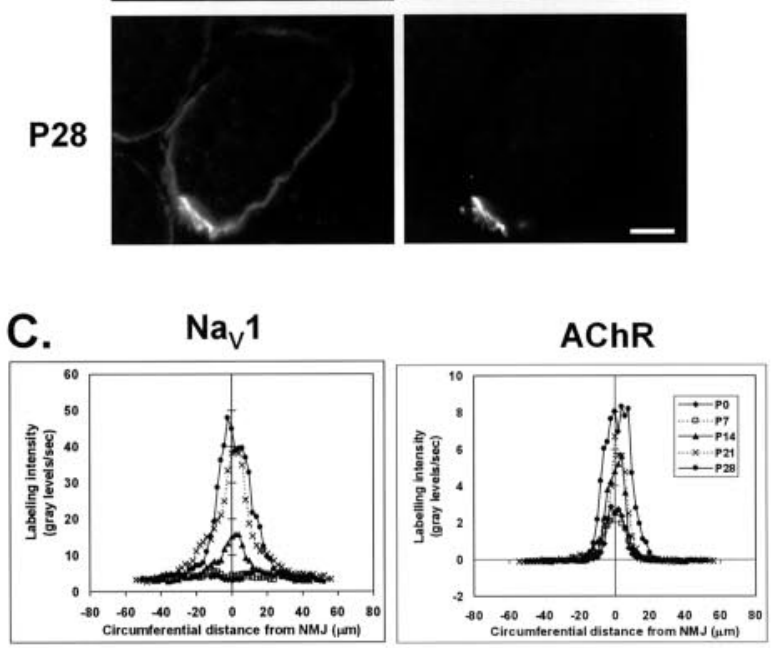

D.

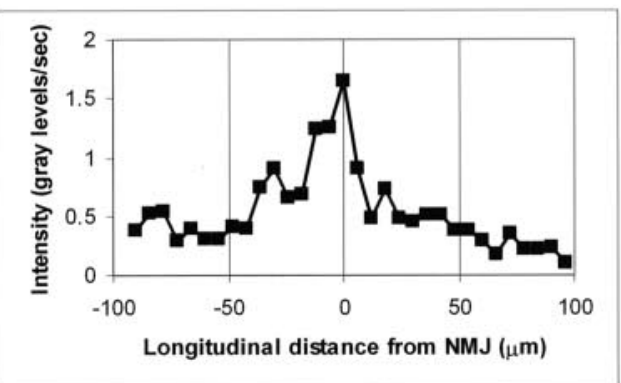

Figure 2. Changes in $\mathrm{Na}_{\mathrm{v}} 1$ distribution during development of rat soleus muscles. $\mathrm{Na}_{\mathrm{v}} 1$ is labeled by an antibody that recognizes all $\mathrm{Na}_{\mathrm{v}} 1$ isoforms. AChRs are labeled by $\alpha$-BgTx. A, NMJs viewed en face in teased fiber preparations show little clustering of $\mathrm{Na}_{v} 1$ in the region of high
A.
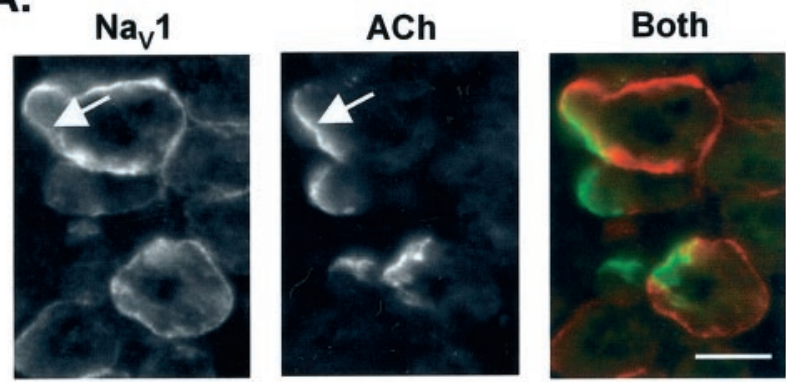

B.

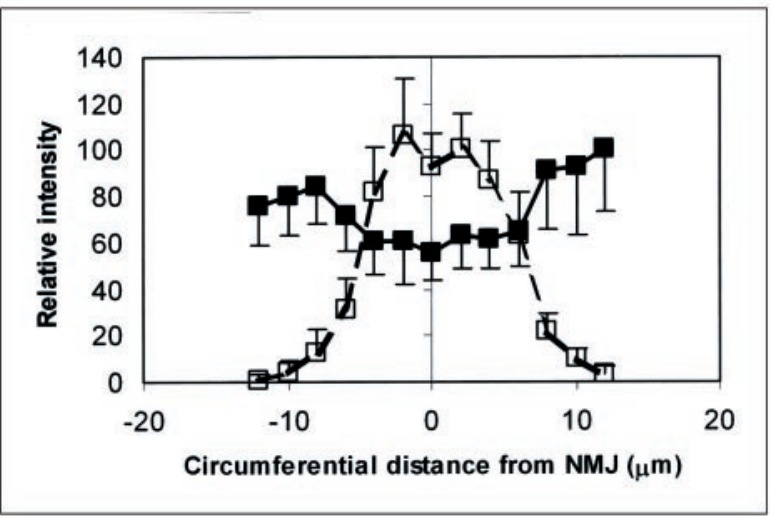

Figure 3. Labeling for $\mathrm{Na}_{\mathrm{V}} 1$ channels is reduced in AChR-rich regions of NMJs in newborn rats. $A$, Example of a muscle fiber profile in which the intensity of $\mathrm{Na}_{v} 1$ labeling appears reduced in the region of highest AChR labeling (arrows). $\mathrm{Na}_{\mathrm{v}} 1$ (red) and $\mathrm{AChR}$ ( green) labeling are superimposed in the image labeled Both. Scale bar, $20 \mu \mathrm{m}$. B, Quantification of the variation in labeling intensity around the circumference of muscle fibers, centered on the NMJ, for $\mathrm{Na}_{\mathrm{v}} 1$ and AChR. Means \pm SEM of data from 12 muscle fibers are shown.

struction of individual fibers using serial transverse sections of muscles from newborn rats (Fig. $2 D$ ). At birth, the perijunctional region of increased $\mathrm{Na}_{\mathrm{V}} 1$ labeling extends along individual muscle fibers for $\sim 50 \mu \mathrm{m}$ in either direction away from the zone of intense AChR labeling at the NMJ, itself some 10-15 $\mu \mathrm{m}$ long.

Segregation of $\mathrm{Na}_{\mathrm{V}} 1$ from $\mathrm{AChR}$ begins before folds form In higher-magnification views of sections through NMJs of newborn rats, it sometimes appeared that the intensity of $\mathrm{Na}_{\mathrm{V}} 1$ labeling was actually reduced in the region of highest AChR density (Fig. 3A). To test the generality of this impression, we compared the averaged profiles of $\mathrm{AChR}$ and $\mathrm{Na}_{\mathrm{V}} 1$ labeling around the circumference of a sample of muscle fibers (Fig. 3B) (see Materials and Methods). Despite the considerable variation in intensity

$\leftarrow$

AChR density until 1-2 weeks after birth. $B$, Transverse sections reveal increased $\mathrm{Na}_{\mathrm{v}} 1$ labeling in the region of innervation at $\mathrm{PO}$, but this labeling is not closely colocalized with the AChRs. Some fibers are strongly labeled although no AChR cluster is present (asterisk). At later postnatal stages, $\mathrm{Na}_{\mathrm{V}} 1$ labeling becomes concentrated at the NMJ and persists in the perijunctional region. C, Circumferential distributions of $A C h R$ and $\mathrm{Na}_{v} 1$ labeling measured around muscle fiber profiles passing through the NMJ (see Materials and Methods, mean intensity of 12-14 muscle fibers) confirm that, in contrast to AChRs, no increase in $\mathrm{Na}_{\mathrm{v}} 1$ labeling is seen at the NMJ until P14. D, Quantification of $\mathrm{Na}_{\mathrm{v}} 1$ labeling in serial transverse sections through the central innervated region of the muscle allows the longitudinal extent of $\mathrm{Na}_{\mathrm{v}} 1$ distribution in individual muscle fibers to be determined (see Materials and Methods, mean profile of nine muscle fibers). The longitudinal extent of AChR labeling of individual NMJs is rarely $>10-15 \mu \mathrm{m}$ at this age. Scale bar: $A, B, 20 \mu \mathrm{m}$. 
A.
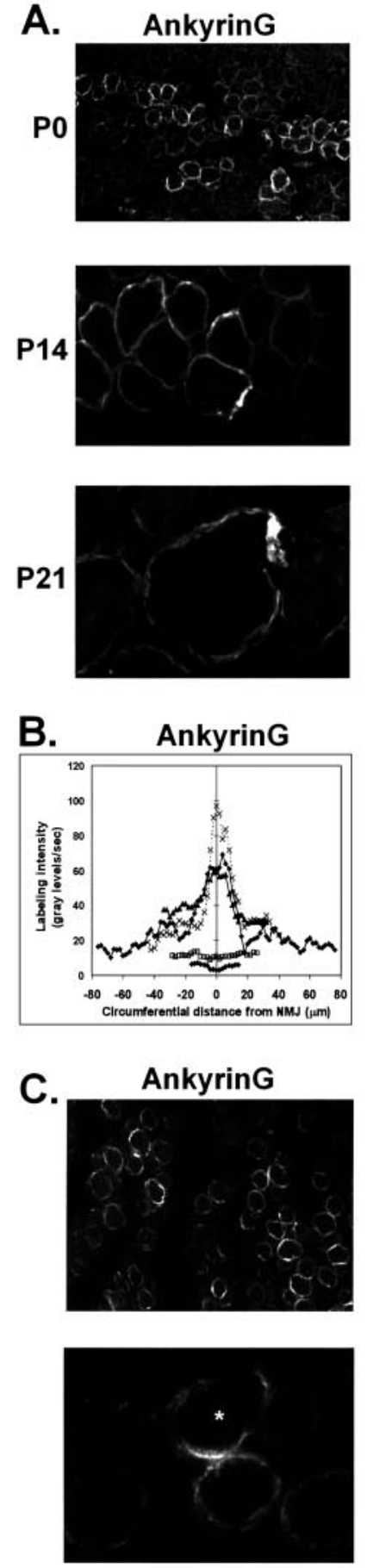

D.

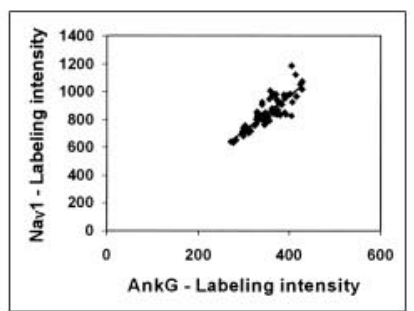

E.

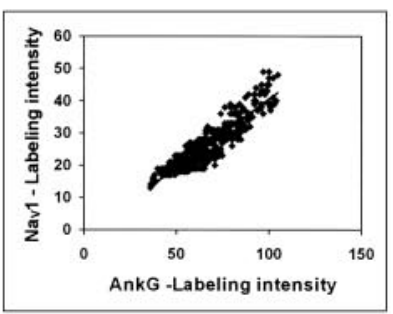

Figure 4. Ankyring distribution at developing rat NMJs. A, At P0, labeling of ankyring is broadly increased in the region of the muscle containing NMJs but is not obviously clustered with the AChRs. By P14, ankyring labeling is increased at the NMJ. B, Circumferential distributions of $A C h R$ and ankyring labeling measured along profiles of muscle fibers passing through from fiber to fiber and around individual fibers, there is a reduction of $\sim 40 \%$ in $\mathrm{Na}_{\mathrm{V}} 1$ labeling in the region of highest AChR labeling. We confirmed this apparently reciprocal relationship by correlation analysis. This revealed a significant $(p<0.001)$ negative correlation between the intensities of $\mathrm{AChR}$ and $\mathrm{Na}_{\mathrm{V}} 1$ labeling at comparable points around the muscle fiber perimeter. At P7, when fold formation has just begun (Bewick et al., 1996), the reduction of $\mathrm{Na}_{\mathrm{V}} 1$ labeling at the NMJ was no longer detectable.

These studies indicate that at birth, when we could first detect $\mathrm{Na}_{\mathrm{V}} 1$ channels by immunolabeling, their distribution differed from that of AChRs in two important ways. First, they were present in a much more diffuse zone, $\sim 100 \mu \mathrm{m}$ long, centered on the NMJ and including the entire circumference of the muscle fiber (diameter, $\sim 10 \mu \mathrm{m}$ ). Second, in the region of nerve contact, the intensity of $\mathrm{Na}_{\mathrm{V}} 1$ labeling was less than in the immediately surrounding perijunctional region, indicating that some segregation of $\mathrm{Na}_{\mathrm{V}} 1$ channels from AChRs was already taking place. We subsequently determined the distributions of ankyrinG and syntrophin to see whether either of these proteins shared these distinctive features with $\mathrm{Na}_{\mathrm{V}} 1$ during the early stages of its accumulation.

\section{AnkyrinG accumulation at developing NMJs parallels that of $\mathrm{Na}_{\mathbf{V}} 1$}

AnkyrinG is present in the membrane skeleton of adult rat muscle fibers and is substantially increased at the adult NMJ (Flucher and Daniels, 1989; Kordeli et al., 1998; Wood and Slater, 1998). During the perinatal period, the pattern of ankyrinG labeling was strikingly similar to that of $\mathrm{Na}_{\mathrm{V}} 1$. At E18, as for $\mathrm{Na}_{\mathrm{V}} 1$ (Wood et al., 1998), there was little or no ankyrinG-specific labeling at the NMJ or elsewhere (data not shown). However, labeling for ankyrinG was clearly present at birth (Figs. 1, 4A). During the next 4 weeks, a localized intense labeling developed at the NMJ in parallel with a general but lesser increase in labeling in the rest of the muscle. Quantitative analysis of the circumferential distribution of ankyrinG confirmed that it differed from that of AChRs in much the same way as $\mathrm{Na}_{\mathrm{V}} 1$ at all times studied (Fig. $4 B$ ).

At birth, some fibers, particularly those with labeled NMJs, were brightly labeled around their entire circumference, whereas others were much more faintly labeled. To determine whether the fibers that were intensely labeled for ankyrinG were the same as those labeled for $\mathrm{Na}_{\mathrm{V}} 1$, we labeled sections with antibodies to both proteins (Fig. 4C). We determined the degree of correlation of the mean intensity of the two labels around a number of muscle fiber profiles. This analysis confirmed that at P0, the correlation between the mean intensity of labeling of ankyrinG around individual fibers and that of $\mathrm{Na}_{\mathrm{V}} 1$ is highly significant (Fig. 4D) ( $p \ll 0.001 ; r=0.746 ; n=65$ fiber profiles). In addition, the variations in intensity of labeling for the two proteins from point to point around the circumference of individual fibers were also highly significantly correlated (Fig. $4 E)(p \ll 0.001$; $r>0.8$ for each of 11 fibers; $>30$ points for each fiber). Thus, in newborn rats, ankyrinG occupies the same extended perijunctional domain as $\mathrm{Na}_{\mathrm{V}} 1$.

\footnotetext{
the NMJ (see Materials and Methods). Means \pm SEM of data from 32 to 86 muscle fibers are shown (mean, 55). Note that, as for $\mathrm{Na}_{\mathrm{v}} 1$, there is no clear increase in ankyrinG at the NMJ until P14. C, Double-immunolabeling of transverse sections shows that the distribution of $\mathrm{Na}_{y} 1$ and ankyrinG is strikingly similar in muscles at P0. At the higher magnification, it can be seen that within individual fibers, there is a similar correspondence of labeling. D, Correlation plot of mean intensity of $\mathrm{Na}_{\mathrm{v}} 1$ labeling versus ankyring labeling for 65 muscle fibers. E, Correlation plot of the intensity of labeling of $\mathrm{Na}_{\mathrm{v}} 1$ and ankyrin $G$ at individual points around the perimeter of the marked fiber (asterisk) in C. Scale bars: $A, 50 \mu \mathrm{m} ; C, 20 \mu \mathrm{m}$.
} 
A.

AnkyrinG
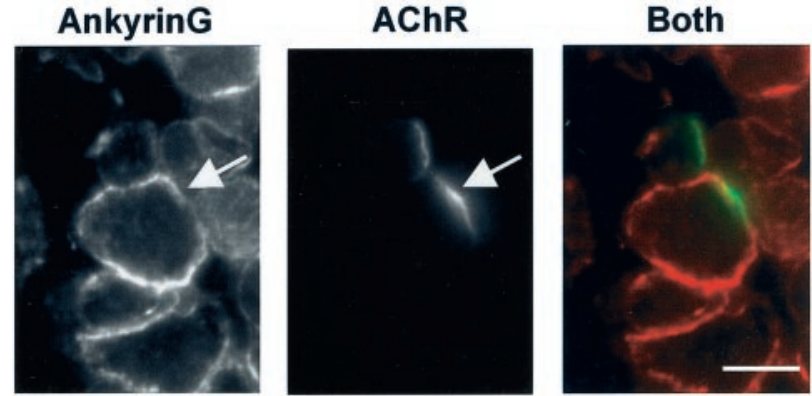

B.

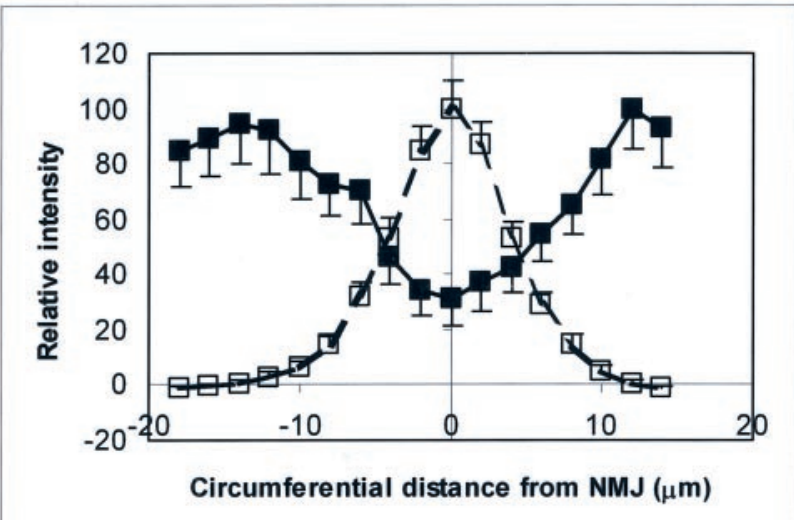

Figure 5. Ankyring labeling is reduced in AChR-rich regions of NMJs in newborn rats. $A$, Example of a muscle fiber profile in which the intensity of ankyring labeling appears reduced in the region of highest AChR labeling (arrows). Ankyring (red) and AChR ( green) labeling are superimposed in the image labeled Both. B, Quantification of the variation in labeling intensity around the circumference of muscle fibers, centered on the NMJ, for ankyring and AChR. Means \pm SEM of data from 49 muscle fibers are shown. Scale bar, $20 \mu \mathrm{m}$.

\section{AnkyrinG is excluded from the region of high AChR density} during early stages of NMJ formation

As with $\mathrm{Na}_{\mathrm{V}} 1$, some images suggested that ankyrinG labeling is reduced in regions of high AChR density (Fig. $5 A$ ). When this impression was tested quantitatively, a reciprocal relationship between ankyrinG and AChR labeling was observed (Fig. 5B), even more striking than that seen for $\mathrm{Na}_{\mathrm{V}} 1$ and AChRs (Fig. $3 B$ ). Thus, labeling for ankyrinG at the center of the NMJ was $70 \%$ less than that at either side. As with $\mathrm{Na}_{\mathrm{V}} 1$, no reduction in labeling intensity at the NMJ was seen at P7 (Fig. 4B).

Here we demonstrate for the first time that in newborn muscles (the earliest time we can detect ankyrinG) and throughout the postnatal period, ankyrinG has a distribution very similar to that of $\mathrm{Na}_{\mathrm{V}} 1 \mathrm{~s}$. This similarity is particularly striking at birth, when it includes the increase in the perijunctional region and the exclusion from the NMJ itself, two key features that distinguish the distribution of $\mathrm{Na}_{\mathrm{V}}$ 1s from that of AChRs.

\section{Syntrophin is concentrated at sites of high AChR density} from an early stage of NMJ development

We studied the changes in syntrophin distribution during the maturation of the NMJ with a monoclonal antibody that recognizes all of the major forms of syntrophin in muscle (Peters et al., 1997). At E18, the earliest time we investigated, syntrophin was already present around the muscle fiber periphery and was concentrated at the NMJ (Fig. 6A). During the first postnatal month,
A.
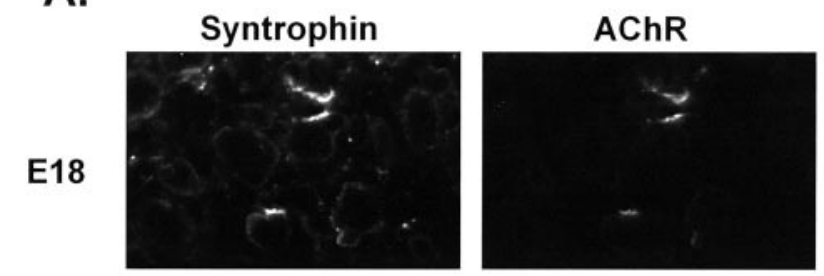

P2
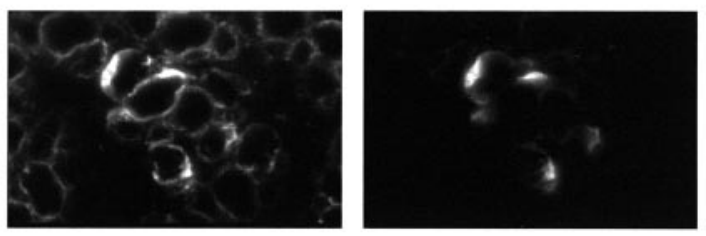

P14
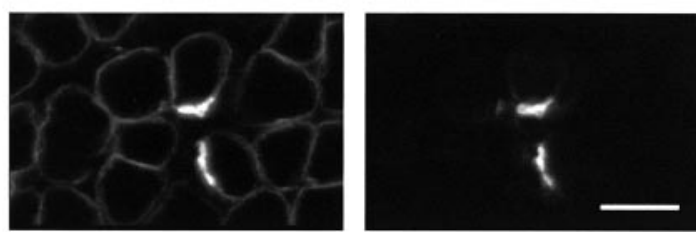

B.
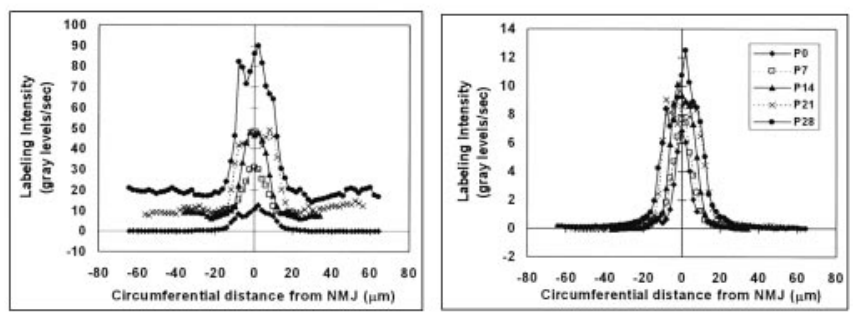

Figure 6. Syntrophin labeling is increased in AChR-rich domains of NMJs in rats from before birth. A, At E18 and throughout postnatal development, syntrophin labeling is present around muscle fibers and is markedly increased at the NMJ. Scale bar, $20 \mu \mathrm{m}$. B, Circumferential distributions of AChR and syntrophin labeling measured around muscle fiber profiles (see Materials and Methods) (mean labeling intensity of 11-25; mean, 15 fibers) confirms that syntrophin and AChR are increased at the NMJ, whereas only syntrophin is increased in nonjunctional membrane.

the intensity of labeling increased both at the NMJ and away from it. At all times the zone of high-intensity syntrophin labeling corresponded closely to that of intense AChR labeling (Fig. 6B).

This correspondence was investigated in detail at $\mathrm{P} 0$, for comparison with ankyrinG (Fig. 7). It is clear that the region of increased syntrophin labeling is virtually identical to that of increased AChR labeling. Thus, the distribution of syntrophin labeling during early NMJ maturation differs markedly from that of $\mathrm{Na}_{\mathrm{V}} 1$ and ankyrinG.

AChRs and $\mathrm{Na}_{\mathrm{V}} 1$ are segregated in the absence of postsynaptic folds at chicken NMJs

The region of high $\mathrm{Na}_{\mathrm{V}} 1$ density is closely associated with the postsynaptic folds at mature NMJs (Haimovich et al., 1987; Flucher and Daniels, 1989; Wood and Slater, 1998). This might indicate that the process that generates the distinct postsynaptic domains occupied by AChRs and $\mathrm{Na}_{\mathrm{V}} 1$ is closely associated with the formation of the folds. However, our observations of developing rat NMJs suggest that the segregation of AChRs and $\mathrm{Na}_{\mathrm{V}} 1$ has already begun at birth, before the start of the main period of 
A.
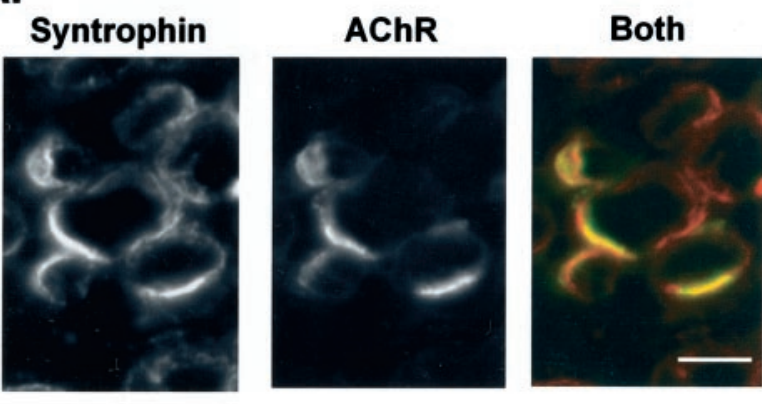

B.

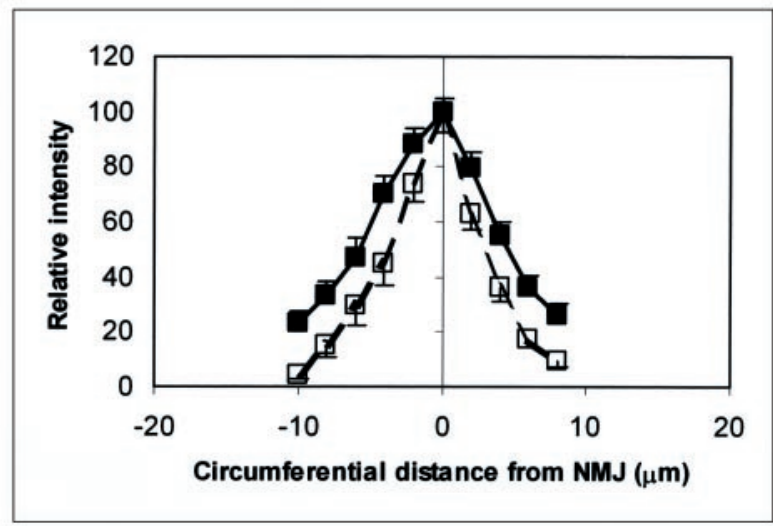

Figure 7. Syntrophin is increased in density in AChR-rich regions of NMJs in newborn rats. $A$, At high magnification, the close correspondence of syntrophin and AChR labeling can be seen. Syntrophin (red) and AChR ( green) labeling overlap ( yellow) in the superimposed image labeled Both. Scale bar, $20 \mu \mathrm{m}$. B, Quantification of the variation in labeling intensity around the circumference of muscle fibers, centered on the NMJ, for syntrophin and AChR. Means $\pm S E M$ of data from 25 muscle fibers are shown.

fold formation (Bewick et al., 1996). At the NMJs of young adult chicken ambiens muscles, although the usual cellular components of the NMJ are present, postsynaptic folds are absent (Fig. $8 A$ ). We examined NMJs in these muscles to see whether, as at NMJs in newborn rats, AChRs and $\mathrm{Na}_{\mathrm{V}} 1$ also occupy distinct domains in the absence of folds.

A region of high AChR labeling, similar to that at all vertebrate NMJs, was present at chicken NMJs (Fig. 8 B). Within this region, the intensity of $\mathrm{Na}_{\mathrm{V}} 1$ labeling was clearly lower than in the surrounding perijunctional region. Thus, as at both immature and mature mammalian NMJs, $\mathrm{Na}_{\mathrm{V}} 1$ and $\mathrm{AChR}$ appear to occupy complementary domains, regardless of whether or not folds are present.

The absence of folds at chicken NMJs might reflect molecular mechanisms for morphogenesis and ion channel localization that differ from those in mammals. Therefore, we were interested in determining the distribution of ankyrinG at these chicken NMJs. Unfortunately, none of the available antibodies recognizes ankyrinG in chickens. As an alternative approach, we studied whether, as in mammals, the two postsynaptic ion channel domains are associated with different underlying cytoskeletal proteins. A clear decrease in the labeling of $\alpha$-fodrin (Fig. 8C), a form of spectrin to which ankyrinG is likely to bind (Jenkins and Bennett, 2001), was observed in the region of high AChR density. In contrast, utrophin, a protein closely associated with the region of high AChR density in mammals (Bewick et al., 1992; Matsumura et al., 1992), occupied precisely the same domain as the AChRs (Fig. 8D). Thus, in these chicken NMJs, in which there are no folds, both the regions of high $\mathrm{Na}_{\mathrm{V}} 1$ and $\mathrm{AChR}$ labeling and the underlying cytoskeletal proteins associated with them are segregated much as they are in young and adult rats.

\section{Discussion}

We have demonstrated that during the development of rats, $\mathrm{Na}_{\mathrm{V}} 1$ channels and AChRs occupy distinct domains at the NMJ as soon as $\mathrm{Na}_{\mathrm{V}} 1$ channels can be detected. Furthermore, in newborn muscles, there is a close colocalization of $\mathrm{Na}_{\mathrm{V}} 1$ channels and ankyrin $G$ in the region of innervation, and both of these proteins are at least partially excluded from the region of highest AChR density. This initial segregation of key postsynaptic proteins does not depend on the folds or the process that generates them, because few folds are present until P7-P14 in rat muscles. This conclusion is also supported by our observation that a similar segregation of ion channel domains is evident at chicken NMJs, which lack folds. The distribution of syntrophin at developing NMJs differs from that of either $\mathrm{Na}_{\mathrm{V}} 1$ channels or ankyrinG. This makes it unlikely that the interaction of $\mathrm{Na}_{\mathrm{V}} 1 \mathrm{~s}$ with syntrophins plays a leading role in the initial segregation of $\mathrm{Na}_{\mathrm{V}} 1$ channels from AChRs or in the initiation of $\mathrm{Na}_{\mathrm{V}} 1$ clustering at the NMJ.

These conclusions are based on the distribution of labeling with antibodies that gave strong signals at immature NMJs. However, these antibodies did not distinguish between the known isoforms of these proteins. Previous studies, using isoformspecific antibodies for $\mathrm{Na}_{\mathrm{V}} 1$ and syntrophins, suggest that in newborn muscles the isoforms characteristic of the adult NMJ $\left(\mathrm{Na}_{\mathrm{V}} 1.4, \beta_{2}\right.$-syntrophin $)$ are present in very low amounts, if at all (Lupa et al., 1993; Kramarcy and Sealock, 2000). Therefore, we believe that the major isoforms of these proteins that we have detected in newborn muscles are $\mathrm{Na}_{\mathrm{V}} 1.5$ and $\alpha$-syntrophin. Alternatively spliced transcripts encoded by the ANK3 gene, which encodes ankyrinG, are expressed in rat skeletal muscle (Kordeli et al., 1998; Gagelin et al., 2002). However, the isoform of ankyrinG present at the NMJ is not yet known.

\section{$\mathrm{Na}_{\mathrm{V}} 1$ and ankyring appear at birth in the region of nerve- muscle contact}

Why are $\mathrm{Na}_{\mathrm{V}} 1 \mathrm{~s}$ and ankyrinG initially expressed only in the region of nerve-muscle contact? One possibility is that the synthesis of these proteins is localized in this region. We have shown recently that mRNAs encoding $\mathrm{Na}_{\mathrm{V}} 1$ are concentrated at the adult NMJ (Awad et al., 2001) and have evidence that this is also true at NMJs in newborn rats (Awad et al., 1999). The zone of increased levels of $\mathrm{Na}_{\mathrm{V}} 1 \mathrm{mRNA}$ at NMJs in adult muscle fibers is a sphere $\sim 25 \mu \mathrm{m}$ in diameter (Awad et al., 2001). An mRNA "cloud" of this volume, if contained within a muscle fiber in a newborn rat with a typical diameter of $10 \mu \mathrm{m}$, would have a longitudinal extent similar to that of the perijunctional region of $\mathrm{Na}_{\mathrm{V}} 1$ labeling we have observed (compare Fig. 2 I). Thus, it seems possible that the extent of increased $\mathrm{Na}_{\mathrm{V}} 1$ density is determined by the distribution of encoding mRNAs, probably itself a result of increased transcription in the synaptic nuclei. A similar mechanism could account for the initial distribution of ankyrinG, but the abundance of ankyrinG mRNAs at the NMJ has not been investigated.

For any membrane protein that is preferentially synthesized near the NMJ, a rate of diffusion in the membrane that is slow relative to its half-life would result in a locally elevated concentration. If $\mathrm{Na}_{\mathrm{V}} 1$ were bound to ankyrinG (see below), the low diffusion coefficient of this complex would favor an accumulation of both $\mathrm{Na}_{\mathrm{V}} 1$ and ankyrinG in the region of the NMJ. 
A. FM1-43 \& AChR

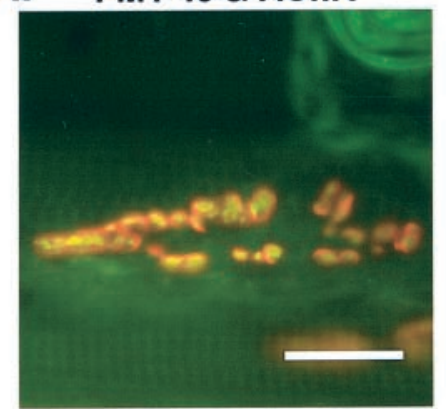

B.

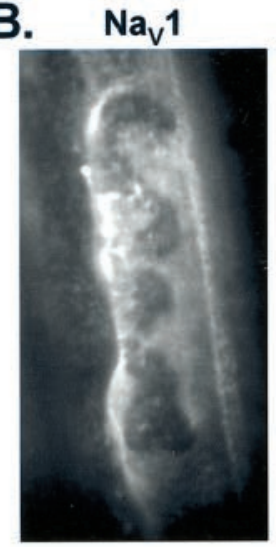

C. $\alpha$-fodrin

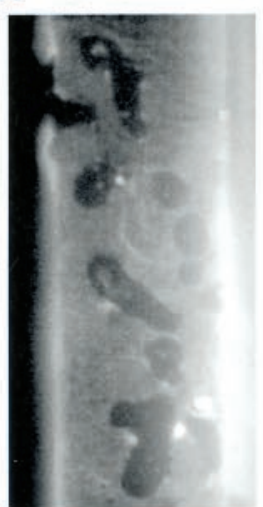

D. Utrophin

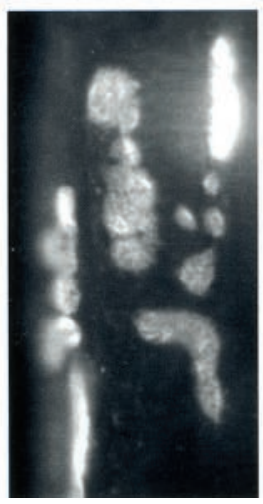

AChR

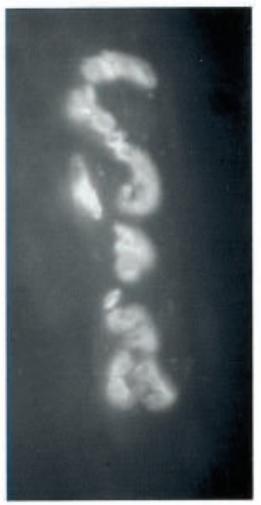

AChR

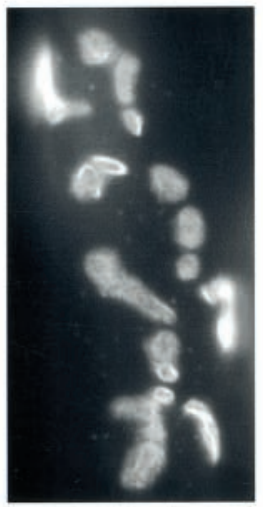

AChR

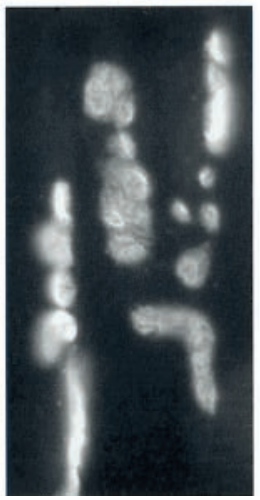

EM
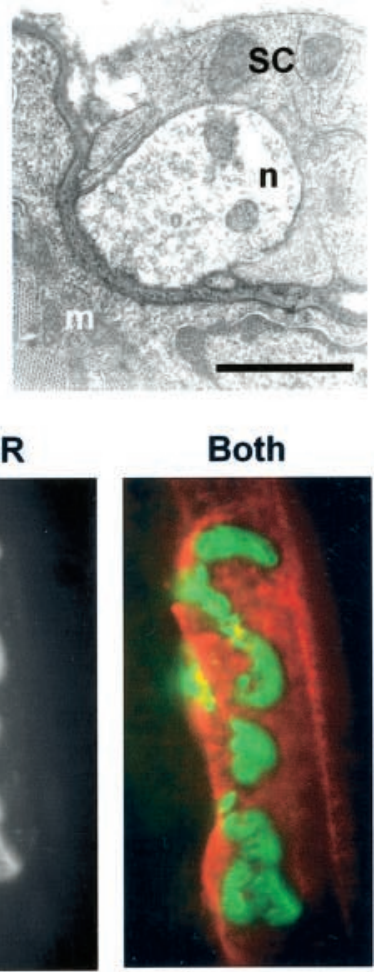

Both

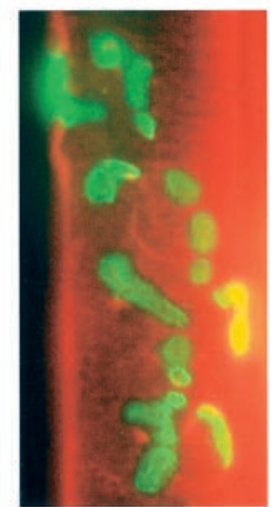

Both

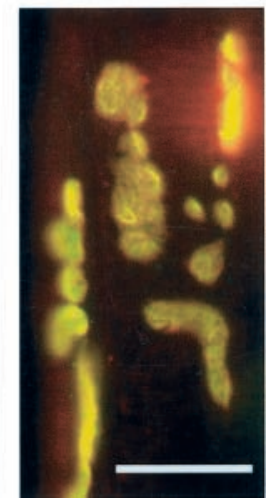

Figure 8. NMJs in young adult chicken ambiens muscle. $A$, Nerve terminals (green) labeled with FM1-43 and AChRs (red) labeled with $\alpha$-BgTx reveal that the overall organization of the chicken NMJ is similar to that in mammals (left). Electron microscopy (EM) reveals the absence of postsynaptic folds (right; $n$, Nerve terminal; SC, Schwann cell; $m$, muscle fiber). $B-D$,
Exclusion of $\mathrm{Na}_{\mathrm{v}} 1$ and ankyring from regions of high $\mathrm{AChR}$ density at birth

A striking feature of our observations is the apparent exclusion of $\mathrm{Na}_{\mathrm{V}} 1$ and ankyrinG from the region of high AChR density at an early stage of NMJ formation. Cross-linking of membrane proteins to the cytoskeleton has been identified as a mechanism for maintaining the segregation of membrane proteins in polarized neurons (Winckler et al., 1994, 1999). The concentration of membrane proteins at the axon initial segment (AIS) linked to specific underlying cytoskeletal proteins impedes diffusion of proteins through the membrane and physically restrains those proteins. Thus, the AIS acts as a boundary between axonal and somatodendritic membrane proteins in rat hippocampal neurons.

At newborn NMJs the AChRs are already clustered at high density and linked, via rapsyn, to a complex including utrophin and other cytoskeletal proteins (for review, see Sanes and Lichtman, 2001). This complex might well form a barrier to the entry of $\mathrm{Na}_{\mathrm{V}} 1$ and ankyrinG, excluding them from the region of high AChR density. If so, the sharp boundary between $\mathrm{Na}_{\mathrm{V}} 1$ and AChR (Flucher and Daniels, 1989) might be maintained primarily by the integrity of the AChR cluster rather than by any active clustering of mobile $\mathrm{Na}_{\mathrm{V}} 1$ molecules.

\section{AnkyrinG may direct $\mathrm{Na}_{\mathrm{V}} \mathrm{l}$ accumulation in both muscle and nerve}

In myelinated axons, as at the $\mathrm{NMJ}, \mathrm{Na}_{\mathrm{V}} 1$ channels are highly concentrated at sites of action potential generation: the axon hillock and AIS (Wollner and Catterall, 1986; Angelides et al., 1988) and the node of Ranvier (Waxman and Ritchie, 1985; Kaplan et al., 1997). In both cases, there is increasing evidence that ankyrinG plays a leading role in a series of events causing $\mathrm{Na}_{\mathrm{V}} 1$ accumulation that may also involve cell adhesion molecules (CAMs; e.g., tenascin, neurofascin) (Lambert et al., 1997) and the spectrinbased membrane skeleton (Berghs et al., 2000).

During postnatal development of the AIS, ankyrinG often appears in advance of $\mathrm{Na}_{\mathrm{V}} 1 \mathrm{~s}$ (Jenkins and Bennett, 2001). In mutant ankyrin-deficient neurons, there is an abnormal distribution of CAMs, $\beta$-spectrin, and $\mathrm{Na}_{\mathrm{V}} 1 \mathrm{~s}$ and an inability to generate action potentials (Zhou et al., 1998; Jenkins and Bennett, 2001). This suggests that an as yet unidentified ankyrinG receptor recruits ankyrinG to the AIS as the first step in $\mathrm{Na}_{\mathrm{V}} 1$ clustering. AnkyrinG may also initiate $\mathrm{Na}_{\mathrm{V}} 1$ clustering at the node of Ranvier (Jenkins and Bennett, 2001). Evidence suggests that CAMs recruit $\mathrm{Na}_{\mathrm{V}} 1 \mathrm{~s}$ to developing nodes (Lambert et al., 1997). AnkyrinG can associate with neurofascin and NrCAM (Davis et al., 1993; Zhang et al., 1998); this precedes the appearance of $\mathrm{Na}_{\mathrm{V}} 1$ s (Lambert et al., 1997; Rasband et al., 1999).

Our results suggest that ankyrinG also plays an important role in $\mathrm{Na}_{\mathrm{V}} 1$ accumulation at the NMJ, but that the details of the process differ from those in axons. In axons, localization of ankyrinG precedes that of $\mathrm{Na}_{\mathrm{V}} 1$, whereas at the $\mathrm{NMJ}$, ankyrinG and $\mathrm{Na}_{\mathrm{V}} 1 \mathrm{~s}$ are colocalized as soon as they can be detected. This suggests that ankyrinG and $\mathrm{Na}_{\mathrm{V}} 1$ bind directly to each other at the earliest stage of $\mathrm{Na}_{\mathrm{V}} 1$ channel clustering. Biochemical evidence exists for an interaction in vitro between the $\mathrm{N}$-terminal end of ankyrin and $\mathrm{Na}_{\mathrm{V}} 1$ (Srinivasan et al., 1992; Bouzidi et al.,

Teased fiber preparations allow NMJs to be viewed en face. In the region of high AChR density, the density of labeling for $\mathrm{Na}_{\mathrm{V}} 1(B)$ and $\alpha$-fodrin is low $(C)$, whereas that for utrophin is high (D). Scale bars: $A$, left, $25 \mu \mathrm{m}$; $A$, right, $1 \mu \mathrm{m}$; (in $D), B-D, 20 \mu \mathrm{m}$. 
2002). Our studies do not indicate where and when in the cell such an interaction might first occur. However, associations between AChRs and rapsyn are thought to occur even before the insertion of AChRs into the plasma membrane (Bignami et al., 1998); the same might be true for $\mathrm{Na}_{\mathrm{V}} 1$ and ankyrinG.

\section{Stabilization of $\mathrm{Na}_{\mathrm{v}} 1$ clusters at maturing NMJs}

We have shown that the well defined clusters of $\mathrm{Na}_{\mathrm{V}} 1$ and ankyrinG characteristic of the mature NMJ first appear when the main phase of postsynaptic fold formation nears completion (see also Lupa et al., 1993). A combination of localized synthesis and exclusion of $\mathrm{Na}_{\mathrm{V}} 1$ from $\mathrm{AChR}$-rich regions could, in principle, account for the high density of $\mathrm{Na}_{\mathrm{V}} 1$ in the depths of the folds at mature NMJs. However, other mechanisms may also be involved. At adult NMJs, $\mathrm{Na}_{\mathrm{V}} 1 \mathrm{~s}$ are colocalized with both ankyrinG and $\beta$-spectrin in the depths of the postsynaptic folds (Flucher and Daniels, 1989; Kordeli et al., 1998; Wood and Slater, 1998). An isoform of $\beta$-spectrin that is highly concentrated at adult NMJs does not appear during development until P7-P14 (Bewick et al., 1996). This suggests that although it has no role in the initiation of $\mathrm{Na}_{\mathrm{V}} 1$ clustering, it may play a role in stabilizing ankyrinG$\mathrm{Na}_{\mathrm{V}} 1$ interactions in the folds during NMJ development. $\beta \mathrm{IV}-$ spectrin is the isoform of $\beta$-spectrin found at the AIS and the nodes of Ranvier (Berghs et al., 2000). The absence of $\beta I V-$ spectrin in neurons leads to a dramatic reduction in ankyrinG and $\mathrm{Na}_{\mathrm{V}} 1$ localization at the AIS (Komada and Soriano, 2002). Thus, it appears that interaction with $\beta$-spectrin(s) plays a role in maintaining $\mathrm{Na}_{\mathrm{V}} 1$ clusters in both nerve and muscle. Other methods, including those with higher spatial resolution than those we have used, will be required to clarify this issue.

Although syntrophins have been shown to bind directly to muscle $\mathrm{Na}_{\mathrm{V}}$ 1s (Gee et al., 1998; Schultz et al., 1998), their role in concentrating $\mathrm{Na}_{\mathrm{V}} 1 \mathrm{~s}$ at the $\mathrm{NMJ}$ remains unclear. Interactions with syntrophin are not required for the association of $\mathrm{Na}_{\mathrm{V}} 1$ with the plasma membrane (Adams et al., 2001). Our findings that syntrophin is already concentrated at the NMJ before birth and does not have the same membrane distribution as ankyrinG or $\mathrm{Na}_{\mathrm{V}} 1$ during the first 2 weeks after birth suggests that syntrophins are unlikely to play a role in initiating $\mathrm{Na}_{\mathrm{V}} 1$ accumulation at the NMJ. However, we cannot exclude the possibility that syntrophins (presumably $\alpha$-syntrophin) (Kramarcy and Sealock, 2000) could help to stabilize ankyrin $\mathrm{G}-\mathrm{Na}_{\mathrm{V}} 1$ interactions at mature NMJs.

In conclusion, our findings indicate that the segregation of $\mathrm{Na}_{\mathrm{V}} 1$ from AChRs begins early in NMJ formation, before the formation of the postsynaptic folds, and involves an association with ankyrinG and the exclusion of both $\mathrm{Na}_{\mathrm{V}} 1$ and ankyrinG from the region of nerve-muscle contact. According to this view, the initial segregation of $\mathrm{Na}_{\mathrm{V}} 1$ from AChRs results primarily from the integrity of the AChR cluster rather than from the trapping of mobile $\mathrm{Na}_{\mathrm{V}} 1$ molecules.

\section{References}

Adams ME, Mueller HA, Froehner SC (2001) In vivo requirement of the $\alpha$-syntrophin PDZ domain for the sarcolemmal localization of nNOS and aquaporin-4. J Cell Biol 155:113-122.

Angelides KJ, Elmer LW, Loftus D, Elson E (1988) Distribution and lateral mobility of voltage-dependent sodium channels in neurons. J Cell Biol 106:1911-1925.

Awad SS, Buckel A, Lightowlers RN, Lømo T, Stocksley MA, Wood SJ, Young C, Slater CR (1999) Accumulation of voltage-gated sodium channels at rat neuromuscular junctions. Soc Neurosci Abstr 25:1021.

Awad SS, Lightowlers RN, Young C, Chrzanowska-Lightowlers ZM, Lomo T, Slater CR (2001) Sodium channel mRNAs at the neuromuscular junc- tion: distinct patterns of accumulation and effects of muscle activity. J Neurosci 21:8456-8463.

Berghs S, Aggujaro D, Dirkx Jr R, Maksimova E, Stabach P, Hermel JM, Zhang JP, Philbrick W, Slepnev V, Ort T, Solimena M (2000) BIV spectrin, a new spectrin localized at axon initial segments and nodes of ranvier in the central and peripheral nervous system. J Cell Biol 151:985-1002.

Betz WJ, Bewick GS (1992) Optical analysis of synaptic vesicle recycling at the frog neuromuscular junction. Science 255:200-203.

Bevan S, Steinbach JH (1977) The distribution of $\alpha$-bungarotoxin binding sites of mammalian skeletal muscle developing in vivo. J Physiol (Lond) 267:195-213.

Bewick GS, Nicholson LV, Young C, O'Donnell E, Slater CR (1992) Different distributions of dystrophin and related proteins at nerve-muscle junctions. NeuroReport 3:857-860.

Bewick GS, Nicholson LV, Young C, Slater CR (1993) Relationship of a dystrophin-associated glycoprotein to junctional acetylcholine receptor clusters in rat skeletal muscle. Neuromuscul Disord 3:503-506.

Bewick GS, Young C, Slater CR (1996) Spatial relationships of utrophin, dystrophin, $\beta$-dystroglycan and $\beta$-spectrin to acetylcholine receptor clusters during postnatal maturation of the rat neuromuscular junction. J Neurocytol 25:367-379.

Bignami F, Camus G, Marchand S, Bailly L, Stetzkowski-Marden F, Cartaud J (1998) Targeting of acetylcholine receptor and $43 \mathrm{kDa}$ rapsyn to the postsynaptic membrane in Torpedo marmorata electrocyte. J Physiol (Paris) 92:177-181.

Bouzidi M, Tricaud N, Giraud P, Kordeli E, Caillol G, Deleuze C, Couraud F, Alcaraz G (2002) Interaction of the Nav1.2a subunit of the voltagedependent sodium channel with nodal ankyrin G. In vitro mapping of the interacting domains and association in synaptosomes. J Biol Chem 277:28996-29004.

Davis JQ, McLaughlin T, Bennett V (1993) Ankyrin-binding proteins related to nervous system cell adhesion molecules: candidates to provide transmembrane and intercellular connections in adult brain. J Cell Biol 121:121-133.

Dugandzija-Novakovic S, Koszowski AG, Levinson SR, Shrager P (1995) Clustering of $\mathrm{Na}^{+}$channels and node of Ranvier formation in remyelinating axons. J Neurosci 15:492-503.

Fertuck HC, Salpeter MM (1974) Localization of acetylcholine receptor by ${ }^{125}$ I-labeled $\alpha$-bungarotoxin binding at mouse motor endplates. Proc Natl Acad Sci USA 71:1376-1378.

Flucher BE, Daniels MP (1989) Distribution of $\mathrm{Na}^{+}$channels and ankyrin in neuromuscular junctions is complementary to that of acetylcholine receptors and the $43 \mathrm{kDa}$ protein. Neuron 3:163-175.

Gagelin C, Constantin B, Deprette C, Ludosky MA, Recouvreur M, Cartaud J, Cognard C, Raymond G, Kordeli E (2002) Identification of Ank(G107), a muscle-specific ankyrin-G isoform. J Biol Chem 277:12978-12987.

Gee SH, Madhavan R, Levinson SR, Caldwell JH, Sealock R, Froehner SC (1998) Interaction of muscle and brain sodium channels with multiple members of the syntrophin family of dystrophin-associated proteins. J Neurosci 18:128-137.

Goldin AL, Barchi RL, Caldwell JH, Hofmann F, Howe JR, Hunter JC, Kallen RG, Mandel G, Meisler MH, Netter YB, Noda M, Tamkun MM, Waxman SG, Wood JN, Catterall WA (2000) Nomenclature of voltage-gated sodium channels. Neuron 28:365-368.

Haimovich B, Schotland DL, Fieles WE, Barchi RL (1987) Localization of sodium channel subtypes in adult rat skeletal muscle using channelspecific monoclonal antibodies. J Neurosci 7:2957-2966.

Jenkins SM, Bennett V (2001) Ankyrin-G coordinates assembly of the spectrin-based membrane skeleton, voltage-gated sodium channels, and L1 CAMs at Purkinje neuron initial segments. J Cell Biol 155:739-746.

Kaplan MR, Meyer-Franke A, Lambert S, Bennett V, Duncan ID, Levinson SR, Barres BA (1997) Induction of sodium channel clustering by oligodendrocytes. Nature 386:724-728.

Komada M, Soriano P (2002) $\beta$ IV-spectrin regulates sodium channel clustering through ankyrin-G at axon initial segments and nodes of Ranvier. J Cell Biol 156:337-348.

Kordeli E, Lambert S, Bennett V (1995) Ankyrin G: a new ankyrin gene with neural-specific isoforms localized at the axonal initial segment and node of Ranvier. J Biol Chem 270:2352-2359.

Kordeli E, Ludosky MA, Deprette C, Frappier T, Cartaud J (1998) Ankyrin $\mathrm{G}$ is associated with the postsynaptic membrane and the sarcoplasmic reticulum in the skeletal muscle fiber. J Cell Sci 111:2197-2207. 
Kramarcy NR, Sealock R (2000) Syntrophin isoforms at the neuromuscular junction: developmental time course and differential localization. Mol Cell Neurosci 15:262-274.

Lambert S, Davis JQ, Bennett V (1997) Morphogenesis of the node of Ranvier: co-clusters of ankyrin and ankyrin-binding integral proteins define early developmental intermediates. J Neurosci 17:7025-7036.

Lupa MT, Krzemien DM, Schaller KL, Caldwell JH (1993) Aggregation of sodium channels during development and maturation of the neuromuscular junction. J Neurosci 13:1326-1336.

Martin AR (1994) Amplification of neuromuscular transmission by postjunctional folds. Proc R Soc Lond B Biol Sci 258:321-326.

Matsumura K, Ervasti JM, Ohlendieck K, Kahl SD, Campbell KP (1992) Association of dystrophin-related protein with dystrophin-associated proteins in mdx mouse muscle. Nature 360:588-591.

Peters MF, Kramarcy NR, Sealock R, Froehner SC (1994) $\beta 2$-Syntrophin: localization at the neuromuscular junction in skeletal muscle. NeuroReport 5:1577-1580.

Peters MF, Adams ME, Froehner SC (1997) Differential association of syntrophin pairs with the dystrophin complex. J Cell Biol 138:81-93.

Rasband MN, Peles E, Trimmer JS, Levinson SR, Lux SE, Shrager P (1999) Dependence of nodal sodium channel clustering on paranodal axoglial contact in the developing CNS. J Neurosci 19:7516-7528.

Salpeter MM (1987) Vertebrate neuromuscular junctions: general morphology, molecular organization, and functional consequences. In: The vertebrate neuromuscular junction (Salpeter MM, ed), pp 1-54. New York: Liss.

Sanes JR, Lichtman JW (1999) Development of the vertebrate neuromuscular junction. Annu Rev Neurosci 22:389-442.

Sanes JR, Lichtman JW (2001) Induction, assembly, maturation and maintenance of a postsynaptic apparatus. Nat Rev Neurosci 2:791-805.

Schultz J, Hoffmuller U, Krause G, Ashurst J, Macias MJ, Schmieder P, Schneider-Mergener J, Oschkinat H (1998) Specific interactions between the syntrophin PDZ domain and voltage-gated sodium channels. Nat Struct Biol 5:19-24.
Slater CR, Lyons PR, Walls TJ, Fawcett PR, Young C (1992) Structure and function of neuromuscular junctions in the vastus lateralis of man: a motor point biopsy study of two groups of patients. Brain 115:451-478.

Srinivasan Y, Lewallen M, Angelides KJ (1992) Mapping the binding site on ankyrin for the voltage-dependent sodium channel from brain. J Biol Chem 267:7483-7489.

Stocksley MA, Slater CR (1999) Failure of action potentials to propagate to the end of newborn rat muscle fibres. J Physiol (Lond) 500:50P.

Waxman SG, Ritchie JM (1985) Organization of ion channels in the myelinated nerve fiber. Science 228:1502-1507.

Winckler B, Gonzalez AC, Magendantz M, Solomon F (1994) Analysis of a cortical cytoskeletal structure: a role for ezrin-radixin-moesin (ERM proteins) in the marginal band of chicken erythrocytes. J Cell Sci 107:2523-2534

Winckler B, Forscher P, Mellman I (1999) A diffusion barrier maintains distribution of membrane proteins in polarized neurons. Nature 397:698-701.

Wollner DA, Catterall WA (1986) Localization of sodium channels in axon hillocks and initial segments of retinal ganglion cells. Proc Natl Acad Sci USA 83:8424-8428.

Wood SJ, Slater CR (1998) $\beta$-Spectrin is colocalized with both voltage-gated sodium channels and ankyrin $\mathrm{G}$ at the adult rat neuromuscular junction. J Cell Biol 140:675-684.

Wood SJ, Slater CR (2001) Safety factor at the neuromuscular junction. Prog Neurobiol 64:393-429.

Wood SJ, Shewry K, Young C, Slater CR (1998) An early stage in sodium channel clustering at developing rat neuromuscular junctions. NeuroReport 9:1991-1995.

Zhang X, Davis JQ, Carpenter S, Bennett V (1998) Structural requirements for association of neurofascin with ankyrin. J Biol Chem 273:30785-30794.

Zhou D, Lambert S, Malen PL, Carpenter S, Boland LM, Bennett V (1998) Ankyrin $\mathrm{G}$ is required for clustering of voltage-gated Na channels at axon initial segments and for normal action potential firing. J Cell Biol 143: 1295-1304. 